\title{
Are three arteries better than two? Impact of using the radial artery in addition to bilateral internal thoracic artery grafting on long-term survival
}

\author{
Umberto Benedetto, MD, PhD, Massimo Caputo, MD, Mustafa Zakkar, PhD, Alan Bryan, MD, and \\ Gianni D. Angelini, MD
}

\begin{abstract}
Objective: Whether radial artery (RA) as third arterial conduit in addition to bilateral internal thoracic artery (BITA) is associated with better survival than saphenous vein $(\mathrm{SV})$ remains undetermined.

Methods: Study population included a selected low-risk group of 275 subjects undergoing BITA grafting with RA as third arterial conduit (BITA+RA) and 489 undergoing BITA grafting with additional SV graft (BITA+SV). RA was considered only for target stenosis of at least $75 \%$. We finally obtained 275 propensity score-matched pairs for comparison.
\end{abstract}

Results: Operative mortalities were $1(0.3 \%)$ and $2(0.7 \%)$ for BITA+RA and BITA + SV, respectively $(P=.56)$. After mean follow-up of $10.6 \pm 4.8$ years, BITA+RA survivals were $97.4 \% \pm 0.9 \%, 90.3 \% \pm 2.0 \%$, and $81.7 \% \pm 3.2 \%$ at 5 , 10 , and 15 years, respectively, versus $97.0 \% \pm 1.0 \%, 94.1 \% \pm 1.5 \%$, and $82.1 \% \pm 3.4 \%$ ( $\log$-rank $P=.54$; hazard ratio, $1.16 ; 95 \%$ confidence interval, 0.71-1.9). Strategies showed comparable survivals when RA or SV was used to graft the right $(P=.79)$ or left $(P=.55)$ coronary system only. Lack of survival advantage for BITA+RA was confirmed in patients 60 years and younger $(P=.80)$ and older than 60 years $(P=.53)$, with and without diabetes mellitus ( $P=.89$ and $P=.54$, respectively), and with or without left ventricular dysfunction $(P=.95$ and $P=.65$, respectively).

Conclusions: Long-term survival in selected low-risk patients undergoing BITA grafting was not extended by using RA as third arterial conduit in preference to SV. (J Thorac Cardiovasc Surg 2016;152:862-9)

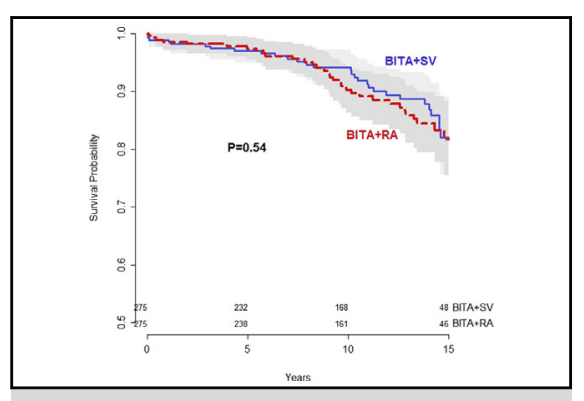

Survival curves in matched groups receiving RA or SV as conduit along with BITA grafting.

\section{Central Message}

Long-term survival in the context of bilateral internal thoracic artery grafting is not extended by using the radial artery in preference to saphenous vein in selected low-risk patients.

\section{Perspective}

Long-term survival in the context of bilateral internal thoracic artery grafting is not extended by using the radial artery as the third arterial conduit in preference to saphenous vein in selected low-risk patients. More data are needed before it is clear whether a venous graft should be preferred as the third conduit in this setting.

See Editorial Commentary page 870.
Late survival after coronary artery bypass grafting (CABG) surgery is improved when the left internal thoracic artery is grafted to the left anterior descending coronary artery. ${ }^{1}$ The right internal thoracic artery has been advocated for further improvement of long-term revascularization outcomes. ${ }^{2}$ Whether the use of the radial artery $(\mathrm{RA})^{3-5}$ as a third

From the Bristol Heart Institute, University of Bristol, School of Clinical Sciences, Bristol, United Kingdom.

This study was supported by the British Heart Foundation (CH/92027/7163) and the NIHR Bristol Cardiovascular Biomedical Research Unit.

Received for publication Jan 18, 2016; revisions received April 11, 2016; accepted for publication April 19, 2016; available ahead of print May 18, 2016.

Address for reprints: Umberto Benedetto, MD, PhD, Bristol Heart Institute, University of Bristol, Upper Maudlin St, Bristol BS2 8HW, United Kingdom (E-mail: umberto.benedetto@bristol.ac.uk).

$0022-5223 / \$ 36.00$

Copyright (c) 2016 by The American Association for Thoracic Surgery

http://dx.doi.org/10.1016/j.jtcvs.2016.04.054 arterial conduit in addition to bilateral internal thoracic artery (BITA) grafting is associated with better survival than BITA plus saphenous vein (SV) remains to be determined, with isolated small series reporting conflicting results. $^{6,7}$

Analyses based on propensity score (PS) matching are emerging as an attractive alternative in view of the paucity of evidence from randomized, controlled trials. ${ }^{8}$ To investigate the impact of using the RA as a third conduit instead of

Scanning this QR code will take you to a procedural video and the supplemental figure and table. 

Abbreviations and Acronyms
$\mathrm{CABG}=$ coronary artery bypass grafting
$\mathrm{RA}=$ radial artery
BITA = bilateral internal thoracic artery
$\mathrm{SV}=$ saphenous vein
PS = propensity score

SV in the context of BITA grafting, we performed a singlecenter long-term PS matching comparison.

\section{METHODS AND METHODS}

The study was conducted in accordance with the principles of the Declaration of Helsinki. The local audit committee approved the study, and the requirement for individual patient consent was waived. We retrospectively analyzed prospectively collected data from The National Institute for Cardiovascular Outcomes Research National Adult Cardiac Surgery Audit registry on 1 June 2015 for all isolated first time CABG procedures performed at the Bristol Heart Institute (Bristol, United Kingdom) from 1996 to April 2015. Reproducible cleaning algorithms were applied to the database and regularly updated as required. Briefly, duplicate records and nonadult cardiac surgery entries were removed; transcriptional discrepancies were harmonized; and clinical conflicts and extreme values were corrected or removed. The data were returned regularly to the local units for validation.

Further details and definition of variables are available at http://www. ucl.ac.uk/nicor/audits/adultcardiac/datasets. Among 12,247 isolated firsttime CABG cases performed at our institution during the study period, we selected subjects who met the following criteria: multivessel coronary disease including left main or left anterior descending coronary artery disease; disease requiring at least 3 grafts; and CABG performed by use of the strategies of BITA grafting and RA as third arterial conduit with or without additional SV grafts (BITA+RA group) or BITA grafting with additional $\mathrm{SV}$ grafts only $(\mathrm{BITA}+\mathrm{SV})$. In this series, the RA was considered only in case of target stenosis of at least $75 \%$, and it was used a free graft proximally connected to the ascending aorta. The internal thoracic artery was used as a pedicle graft that remained proximally connected to its respective subclavian artery (in situ) or as a free graft proximally connected to another internal thoracic artery.

\section{Experimental Conduit Harvesting Technique}

During the study period the saphenous vein was exposed by a continuous longitudinal incision, the adventitial layer was stripped, and the side branches were ligated. The vein was removed from the leg immediately after dissection and was manually gently distended by means of a syringe with heparinized normal saline solution or by connecting it to the ascending aorta (Video 1). After distention, the vein was stored in the same fluid use to distend the vein at room temperature, as previously described elsewhere. ${ }^{9}$ For the RA, if the results of the Allen test were normal in both upper extremities, the monodominant extremity was selected and the conduit was harvested with an open technique, as previously described elsewhere. ${ }^{10}$

\section{Pretreatment Variables and Study End Points}

The effect of adding the RA as a third arterial conduit instead of the use of SV was adjusted for the following 25 pretreatment variables: age, sex, body mass index; Canadian Cardiovascular Society grade III or IV; New York Heart Association functional class III or IV; previous myocardial infarction and myocardial infarction within 30 days, previous percutaneous coronary intervention; diabetes mellitus with oral treatment or with insulin therapy; chronic obstructive pulmonary disease; hypertension; current smoking; serum creatinine level of at least $200 \mathrm{mmol} / \mathrm{L}$; previous cerebrovascular accident; peripheral vascular disease; preoperative atrial fibrillation; left main disease; non-left anterior descending coronary artery vessel disease including diagonal, circumflex, or right coronary artery disease; moderate left ventricular dysfunction; severe left ventricular dysfunction; nonelective priority; off-pump CABG; and era of surgery (1996-2004 vs 2005-2015).

The short-term outcomes investigated were as follows: the incidence of re-exploration for bleeding, need for sternal reconstruction, postoperative cerebrovascular accident, postoperative renal replacement therapy, need for postoperative intra-aortic balloon pump, and in-hospital mortality. Long-term outcome investigated was all-cause late mortality. All-cause death is considered the most robust and unbiased index in cardiovascular research because no adjudication is required, thus avoiding inaccurate or biased documentation and clinical assessments. ${ }^{11}$ Information about postdischarge mortality tracking was available for all patients (100\%) and was obtained by linking the institutional database with the National General Register Office.

\section{Statistical Analysis}

For baseline characteristics, variables are summarized as means for continuous variables and proportions for categorical variables. Multiple imputation was used to address missing data (http://www.jstatsoft.org/ $\mathrm{v} 45 / \mathrm{i} 07 /$ ). Information regarding baseline creatinine level showed the higher rate of missing information $(87 / 764 ; 11 \%$; Figure E1 and Table E1). To control for measured potential confounders in the data set, a PS was generated for each patient from a multivariable logistic regression model that was based on pretreatment covariates as independent variables with treatment type (BITA+RA vs BITA $+\mathrm{SV})$ as a binary dependent variable (http://CRAN.Rproject.org/package=nonrandom). ${ }^{12}$ The resulting PS represented the probability of a patient undergoing CABG with BITA + RA grafting. Pairs of patients undergoing BITA + RA and BITA + SV grafting were derived with greedy 1:1 matching with a caliper of width of 0.2 SD of the logit of the PS. The quality of the match was assessed by comparing selected pretreatment variables in PS-matched patients by using the standardized mean difference, by which an absolute standardized difference of greater than $10 \%$ is suggested to represent meaningful covariate imbalance. ${ }^{13}$ Analytic methods for the estimation of the treatment effect in the matched sample included the McNemar test to compare proportions. Kaplan-Meier survival curves between treated and untreated subjects in the matched sample were compared by using a test described by Klein and Moeschberger (http://CRAN.R-project.org/package=survival). ${ }^{12}$ As sensitivity analysis, to address the limited sample size in part, we performed a time-segmented Cox analysis on early (within 30 days) and late (beyond 30 days) mortalities by regressing the outcome on 2 independent variables: the treatment assignment $(\mathrm{BITA}+\mathrm{RA}$ vs $\mathrm{BITA}+\mathrm{SV})$ and the estimated PS. ${ }^{12}$

\section{RESULTS}

The study population included 275 subjects who underwent BITA grafting with the RA as a third arterial conduit with $(n=41)$ or without $(n=234)$ additional SV grafts (BITA + RA group) and 489 subjects who underwent BITA grafting with additional SV graft only (BITA+SV). Patients characteristics distribution before and after PS matching are summarized in Table 1. Patients who received the RA grafts presented a low risk profile. In the unmatched group, BI$\mathrm{TA}+\mathrm{SV}$ tended to be associated with a higher burden of comorbidities. After matching, the groups were comparable for all pretreatment variables. 
TABLE 1. Pretreatment variable distribution in the bilateral internal thoracic artery plus radial artery group and in the unmatched and matched bilateral internal thoracic artery plus saphenous vein groups

\begin{tabular}{|c|c|c|c|c|c|c|c|c|c|c|}
\hline & \multicolumn{2}{|c|}{ BITA $+R A(N=275)$} & \multicolumn{2}{|c|}{$\begin{array}{c}\text { Unmatched BITA }+ \text { SV } \\
(\mathbf{N}=\mathbf{4 8 9})\end{array}$} & \multirow[b]{2}{*}{ SMD } & \multirow[b]{2}{*}{$P$ value } & \multicolumn{2}{|c|}{$\begin{array}{c}\text { Matched BITA }+ \text { SV } \\
(\mathbf{N}=\mathbf{2 7 5}) \\
\end{array}$} & \multirow[b]{2}{*}{ SMD } & \multirow[b]{2}{*}{$P$ value } \\
\hline & No. & $\%$ & No. & $\%$ & & & No. & $\%$ & & \\
\hline Age (y) & & & & & 8 & .3 & & & 7 & .4 \\
\hline$<60$ & 176 & 64.0 & 317 & 64.8 & & & 181 & 65.8 & & \\
\hline $60-69$ & 70 & 25.5 & 142 & 29.0 & & & 78 & 28.4 & & \\
\hline $70-79$ & 28 & 10.2 & 26 & 5.3 & & & 12 & 4.4 & & \\
\hline$\geq 80$ & 1 & 0.4 & 4 & 0.8 & & & 4 & 1.5 & & \\
\hline Female & 18 & 6.5 & 29 & 5.9 & 3 & .8 & 16 & 5.8 & 3 & .8 \\
\hline $\mathrm{BMI} \geq 30 \mathrm{~kg} / \mathrm{m}^{2}$ & 59 & 21.5 & 110 & 22.5 & 13 & .08 & 49 & 17.8 & 2 & .8 \\
\hline CCS III/IV & 114 & 41.5 & 224 & 45.8 & 8 & .3 & 114 & 41.5 & 0 & $>.999$ \\
\hline NYHA III/IV & 70 & 25.5 & 87 & 17.8 & 19 & .01 & 66 & 24.0 & 3 & .7 \\
\hline Past MI & 115 & 41.8 & 220 & 45.0 & 6 & .44 & 115 & 41.8 & 0 & $>.999$ \\
\hline MI within $30 \mathrm{~d}$ & 34 & 12.4 & 89 & 18.2 & 16 & .04 & 36 & 13.1 & 2 & .9 \\
\hline Past PCI & 6 & 2.2 & 23 & 4.7 & 14 & .1 & 5 & 1.8 & 3 & $>.999$ \\
\hline DM-O & 13 & 4.7 & 12 & 2.5 & 12 & .13 & 11 & 4.0 & 4 & .83 \\
\hline DM-I & 5 & 1.8 & 12 & 2.5 & 4 & .75 & 4 & 1.5 & 3 & $>.999$ \\
\hline Hypertension & 171 & 62.2 & 317 & 64.8 & 5 & .51 & 177 & 64.4 & 5 & .65 \\
\hline Smoking & 47 & 17.1 & 77 & 15.7 & 4 & .70 & 49 & 17.8 & 2 & .91 \\
\hline Creatinine $\geq 200 \mathrm{mmol} / \mathrm{L}$ & 1 & 0.4 & 2 & 0.4 & 1 & $>.999$ & 2 & 0.7 & 5 & $>.999$ \\
\hline COPD & 8 & 2.9 & 22 & 4.5 & 8 & .37 & 7 & 2.5 & 2 & $>.999$ \\
\hline CVA & 10 & 3.6 & 17 & 3.5 & 1 & $>.999$ & 11 & 4.0 & 2 & $>.999$ \\
\hline PVD & 17 & 6.2 & 24 & 4.9 & 6 & .56 & 16 & 5.8 & 2 & $>.999$ \\
\hline $\mathrm{AF}$ & 5 & 1.8 & 4 & 0.8 & 8 & .38 & 4 & 1.5 & 3 & $>.999$ \\
\hline LMD & 52 & 18.9 & 96 & 19.6 & 2 & .8 & 57 & 20.7 & 6 & .7 \\
\hline \multicolumn{11}{|l|}{ Vessel diseased } \\
\hline $\mathrm{CX}$ & 262 & 95.3 & 460 & 94.1 & 5 & .6 & 265 & 96.4 & 4 & .7 \\
\hline DIA & 57 & 20.7 & 152 & 31.1 & 23 & .003 & 57 & 20.7 & 0 & $>.999$ \\
\hline $\mathrm{RCA}$ & 248 & 90.2 & 430 & 87.9 & 7 & .4 & 250 & 90.9 & 2 & .9 \\
\hline \multicolumn{11}{|l|}{ LV function } \\
\hline EF 0.30-0.49 & 30 & 10.9 & 74 & 15.1 & 13 & .13 & 24 & 8.7 & 7 & .47 \\
\hline $\mathrm{EF}<0.30$ & 3 & 1.1 & 6 & 1.2 & 1 & $>.999$ & 4 & 1.5 & 3 & $>.999$ \\
\hline Nonelective & 112 & 40.7 & 210 & 42.9 & 5 & .6 & 110 & 40.0 & 1 & .9 \\
\hline Performed by trainee & 93 & 33.8 & 207 & 42.3 & 17 & .02 & 93 & 33.8 & 1 & $>.999$ \\
\hline OPCAB & 103 & 37.5 & 209 & 42.7 & 11 & .2 & 110 & 40.0 & 5 & .6 \\
\hline Era of surgery & & & & & 6 & .3 & & & 2 & .7 \\
\hline 1996-2005 & 176 & 64.0 & 296 & 60.5 & & & 167 & 60.7 & & \\
\hline $2006-2015$ & 99 & 36.0 & 193 & 39.5 & & & 108 & 39.3 & & \\
\hline
\end{tabular}

BITA, Bilateral internal thoracic artery; $R A$, radial artery; $S V$, saphenous vein; $S M D$, standardized mean difference; $B M I$, body mass index; $C C S$, Canadian Cardiovascular Society class; NYHA, New York Heart Association functional class; $M I$, myocardial infarction; $P C I$, percutaneous coronary intervention; $D M$ - $O$, diabetes mellitus with oral treatment; $D M-I$, diabetes mellitus with insulin treatment; COPD, chronic obstructive pulmonary disease; $C V A$, previous cerebrovascular accident; $P V D$, peripheral vascular disease; $A F$, preoperative atrial fibrillation; $L M D$, left main disease; $C X$, circumflex coronary artery; $D I A$, diagonal coronary artery; $R C A$, right coronary artery; $L V$, left ventricle; $E F$, ejection fraction; $O P C A B$, off-pump coronary artery bypass grafting.

\section{Intraoperative Data}

Grafts target in the unmatched and matched groups are summarized in Table 2. Mean numbers of graft performed were $3.26 \pm 0.5$ in the BITA + RA group versus $3.33 \pm 0.5$ and $3.28 \pm 0.5$ in the unmatched $(P=.06)$ and matched $(P=.66)$ BITA $+\mathrm{SV}$ groups, respectively. The RA was used to graft the lateral wall territory in $150(54 \%)$ cases and the right coronary system in the remaining $125(45 \%)$ cases. Overall, the target distributions for the left internal thoracic artery and the right internal thoracic artery were comparable between the groups.

\section{Operative Outcomes}

Operative outcomes are summarized in Table 3. Inhospital mortality occurred in 4 cases $(0.5 \%)$, with 1 death $(0.3 \%)$ in the BITA+RA group and 3 deaths $(0.6 \%)$ in the unmatched BITA $+\mathrm{SV}$ group $(P>.999)$. After matching, the groups were comparable for all operative outcomes investigated. It is notable that the rate of sternal wound reconstruction was particularly low in both groups.

\section{Long-Term Survival}

The mean follow-ups among survivors were $10.6 \pm 4.8$ years (maximum 17.3 years) overall and $10.5 \pm 4.5$ years 
TABLE 2. Grafts target in the bilateral internal thoracic artery plus radial artery group and in the unmatched and matched bilateral internal thoracic artery plus saphenous vein groups

\begin{tabular}{|c|c|c|c|}
\hline & $\begin{array}{c}\text { BITA }+ \text { RA } \\
(\mathbf{N}=\mathbf{2 7 5}) \\
\end{array}$ & $\begin{array}{c}\text { Unmatched } \\
\text { BITA+SV } \\
(\mathbf{N}=\mathbf{4 8 9})\end{array}$ & $\begin{array}{c}\text { Matched } \\
\text { BITA+SV } \\
(\mathbf{N}=\mathbf{2 7 5})\end{array}$ \\
\hline \multicolumn{4}{|l|}{ RA target } \\
\hline CX/DIA & $150(54 \%)$ & - & - \\
\hline $\mathrm{RCA}$ & $125(45 \%)$ & - & - \\
\hline \multicolumn{4}{|l|}{ SV target } \\
\hline CX/DIA & $29(10 \%)$ & $293(60 \%)$ & $117(43 \%)$ \\
\hline $\mathrm{RCA}$ & $12(4 \%)$ & $217(44 \%)$ & $129(47 \%)$ \\
\hline $\mathrm{CX}+\mathrm{RCA}$ & & $70(14 \%)$ & $26(9 \%)$ \\
\hline \multicolumn{4}{|l|}{ LITA target } \\
\hline LAD in situ & $199(72 \%)$ & $345(71 \%)$ & $203(74 \%)$ \\
\hline CX/DIA in situ & $76(28 \%)$ & $144(29 \%)$ & $72(26 \%)$ \\
\hline \multicolumn{4}{|l|}{ RITA target } \\
\hline LAD in situ & $70(25 \%)$ & $128(26 \%)$ & $64(23 \%)$ \\
\hline LAD free & & $8(2 \%)$ & $3(1 \%)$ \\
\hline CX/DIA in situ & $54(20 \%)$ & $162(33 \%)$ & $95(35 \%)$ \\
\hline CX/DIA free & $38(14 \%)$ & $66(13 \%)$ & $32(11 \%)$ \\
\hline RCA in situ & $98(36 \%)$ & $103(21 \%)$ & $67(24 \%)$ \\
\hline RCA free & $15(5 \%)$ & $22(0.5 \%)$ & $14(6 \%)$ \\
\hline
\end{tabular}

and $10.5 \pm 4.9$ years in the BITA $+\mathrm{RA}$ and BITA $+\mathrm{SV}$ groups, respectively. In the BITA + RA group, the survivals at 5,10 , and 15 years were $97.4 \% \pm 0.9 \%, 90.3 \% \pm 2.0 \%$, and $81.7 \% \pm 3.2 \%$, respectively. In the unmatched BITA $+\mathrm{SV}$ group, the survivals at 5,10 , and 15 years were $96.8 \% \pm 0.8 \%, 93.6 \% \pm 0.1 \%$ and $83.8 \% \pm 2.5 \%$, respectively (log-rank $P=.36$ vs BITA $+\mathrm{SV}$ group). In the matched $\mathrm{BITA}+\mathrm{SV}$ group, the survivals at 5,10 , and 15 years were $97.0 \% \pm 1.0 \%, 94.1 \% \pm 1.5 \%$, and $82.1 \% \pm 3.4 \%$, respectively (log-rank $P=.54$; hazard ratio $1.16 ; 95 \%$ confidence interval, 0.71-1.91 vs BITA+SV group; Figure 1, left). When the analysis was restricted to patients in the BITA+RA group who underwent total arterial revascularization only by excluding cases with any additional SV grafting $(n=41)$, the strategies continued to show comparable survivals $(P=.34$; Figure 1, right $)$. The strategies showed comparable survival probabilities when RAs or SVs were used to graft the right coronary system only $(P=.79)$ or the left coronary system only $(P=.55)$ (Figure 2$)$ or when used in the context of in situ BITA grafting $(P=.93)$ or with a free right internal thoracic artery $(P=.30$; Figure 3$)$. Time-segmented, PSadjusted Cox regression models showed that the use of the RA did not significantly affect early (hazard ratio $0.29 ; 95 \%$ confidence interval $0.03-2.72 ; P=.28$ ) and late (hazard ratio $1.27 ; 95 \%$ confidence interval $0.79-2.04 ; P=.32$ ) mortalities (Figure 4).

\section{DISCUSSION}

The main finding of this study is that in a selected lowrisk group of patients undergoing BITA grafting, the addition of the RA as a third arterial conduit was not associated with improved long-term survival relative to a matched group of patients undergoing BITA grafting with additional SV grafting only. The lack of survival benefit was present when the RA was used to graft both the left and the right coronary systems. In addition, when the analysis was restricted to patients undergoing total arterial revascularization with BITA and RA without any additional SV graft, late survivals remained comparable to those observed in subjects undergoing BITA with additional SV grafts only. Furthermore, $\mathrm{BITA}+\mathrm{RA}$ and $\mathrm{BITA}+\mathrm{SV}$ groups showed comparable operative outcomes.

There remains controversy as to whether the use of the RA instead of SV in BITA grafting is associated with further improvement in long-term outcomes. To date, 3 small series have reported on the direct comparison between the RA and $\mathrm{SV}$ in addition to BITA grafting, with conflicting results. Di Mauro and colleagues ${ }^{4}$ reported survivals at 8 years of $91.9 \% \pm 2.9 \%$ among 87 patients undergoing BITA + RA grafting and $95.6 \% \pm 0.9 \%$ among patients undergoing BI$\mathrm{TA}+\mathrm{SV}$ grafting $(P=.12)$. More recently, Grau and coworkers ${ }^{6}$ published a series of 183 patients undergoing $\mathrm{BITA}+\mathrm{RA}$ grafting. Long-term survivals in the BITA $+\mathrm{RA}$ groups were comparable to those in the $\mathrm{BITA}+\mathrm{SV}$ groups $(P=.25)$, although at 10 years the survival curves of the groups crossed, and between 10 and 14 years the BITA+RA group demonstrated higher survival $(P=.04)$. The

TABLE 3. Operative outcomes in the bilateral internal thoracic artery plus radial artery group and in the unmatched and matched bilateral internal thoracic artery plus saphenous vein groups

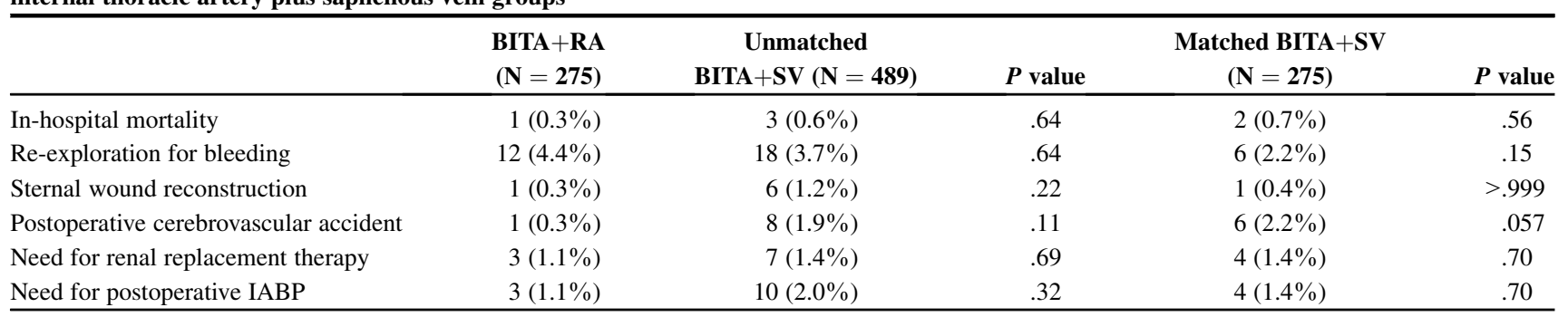

BITA, Bilateral internal thoracic artery; $R A$, radial artery; $S V$, saphenous vein; $I A B P$, intra-aortic balloon pump. 

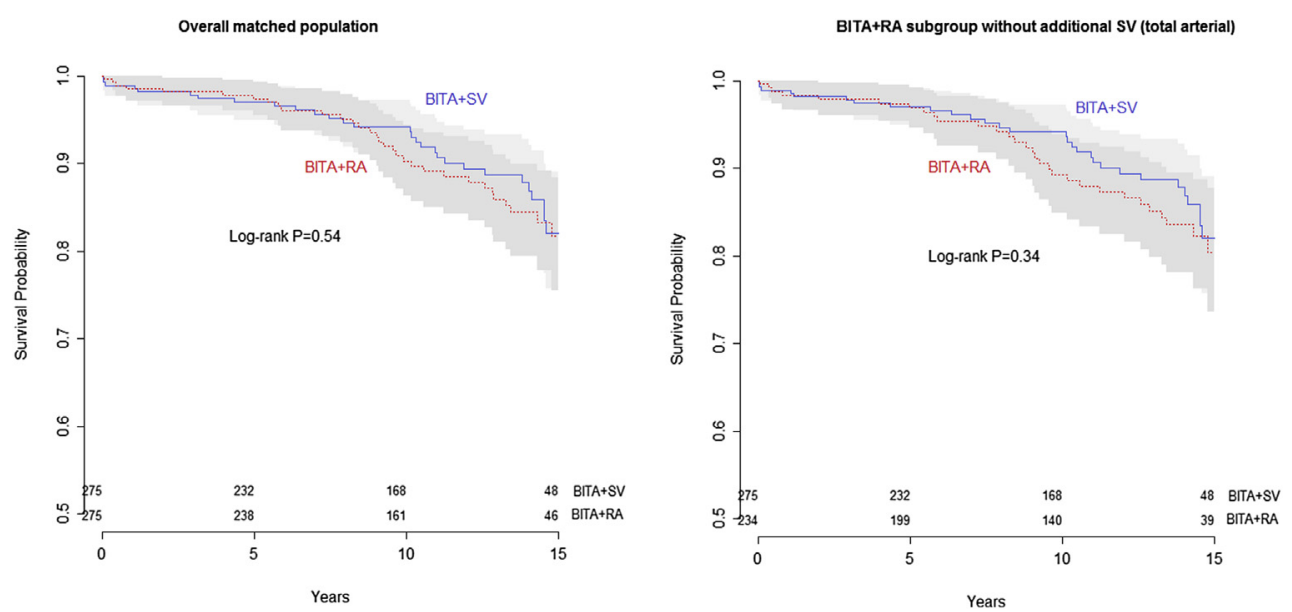

FIGURE 1. Survival curve comparisons between the bilateral internal thoracic artery plus radial artery $(B I T A+R A)$ and bilateral internal thoracic artery plus saphenous vein $(B I T A+S V)$ groups in the overall matched samples (left) and with the bilateral internal thoracic artery plus radial artery subgroup with total arterial revascularization (no saphenous vein $[S V]$; right).

phenomenon of crossing survival curves is common when a treatment is associated with decreased early survival but may offer long-term benefit. The observed trend of decreased early survival in patients undergoing grafting with the RA instead of SV is likely to be related to selection bias. In fact, the use of the RA per se does not increase operative mortality, ${ }^{14}$ and the RA patency has been demonstrated to be noninferior to SV patency at early angiographic follow-up. ${ }^{15}$ Mohammadi and associates ${ }^{7}$ recently reported comparable long-term survivals in 249 matched pairs of patients undergoing BITA+RA versus BI$\mathrm{TA}+\mathrm{SV}$ grafting $(P=.44)$. The main limitation of that study is that many of the RA grafts $(41.4 \%)$ were placed to noncritical coronary targets (ie, stenosis of $50 \%-70 \%$ ). It has largely been demonstrated that the degree of proximal stenosis affects RA performance, ${ }^{16,17}$ and this limitation makes it difficult to interpret these findings.

To the best of our knowledge, ours is the largest matched series reported on the use of RA as a third arterial conduit instead of additional SV graft in the context of BITA grafting where the RA has been used to graft vessels with at least $75 \%$ proximal stenosis in all cases, thus fulfilling current recommendations for the use of the RA. ${ }^{14,15}$ We found that the use of the RA did not increase operative risk, although we did find a trend toward a higher rate of re-exploration for bleeding in the BITA+RA groups, suggesting the need for extra attention during hemostasis when using 3 arterial conduits. Of note, the incidence of sternal wound reconstruction observed in this series was particularly low, thus confirming that the use of BITA
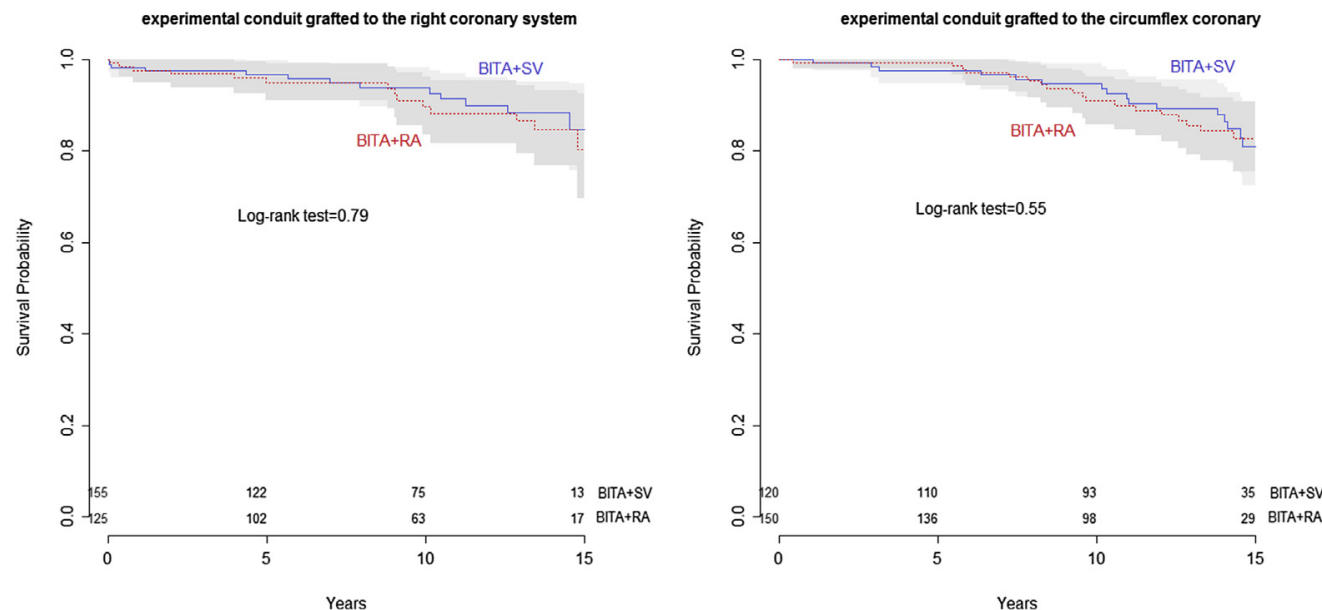

FIGURE 2. Survival curve comparisons between the bilateral internal thoracic artery plus radial artery $(B I T A+R A)$ and bilateral internal thoracic artery plus saphenous vein $(B I T A+S V)$ groups according to the third conduit target. 

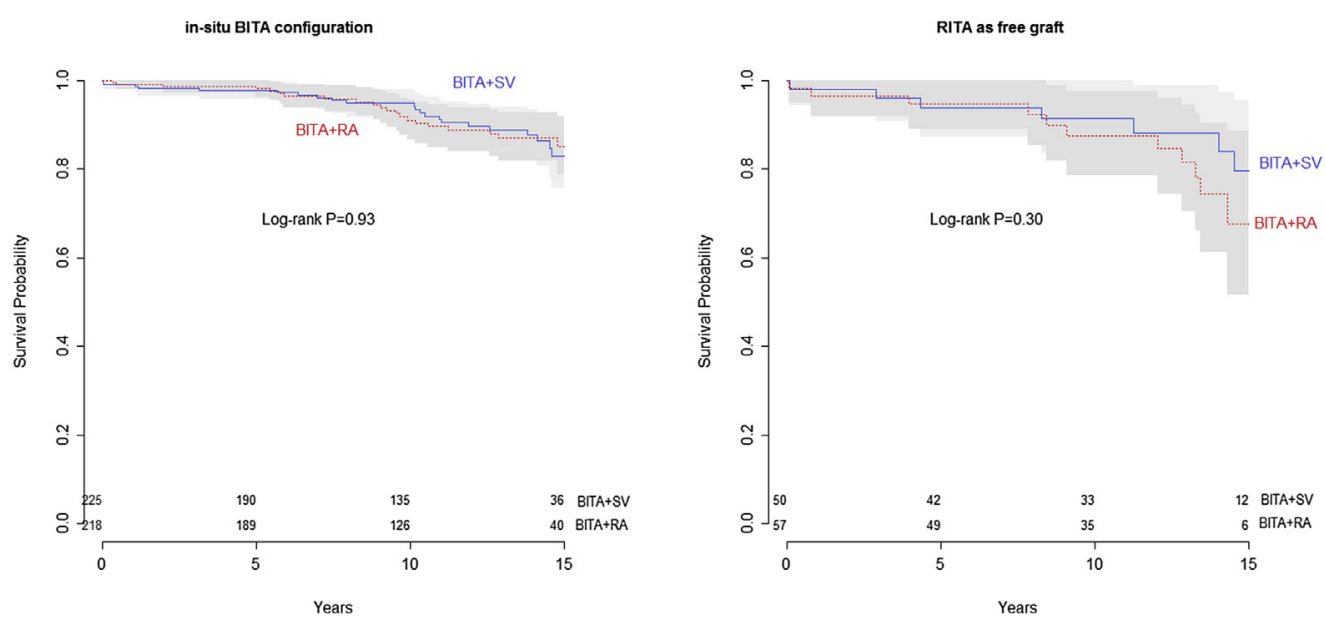

FIGURE 3. Survival curve comparisons between bilateral internal thoracic artery plus radial artery $(B I T A+R A)$ and bilateral internal thoracic artery plus saphenous vein $(B I T A+S V)$ groups according to bilateral internal thoracic artery $(B I T A)$ in situ configuration versus right internal thoracic artery $(R I T A)$ as free graft.

grafting is safe in a low-risk population (overall prevalence of diabetes on insulin approximately $2 \%$ ). ${ }^{18}$

Long-term survival analysis, however, showed that the additional of use of RA in this low-risk population was not associated with a survival benefit during 15 years of follow-up, and this result was seen when the RA was used to graft both the left and the right coronary systems. Moreover, the RA also did not improve survival in cases of total arterial revascularization without additional SV grafts.

\section{Cox regression curves adjusted for PS}

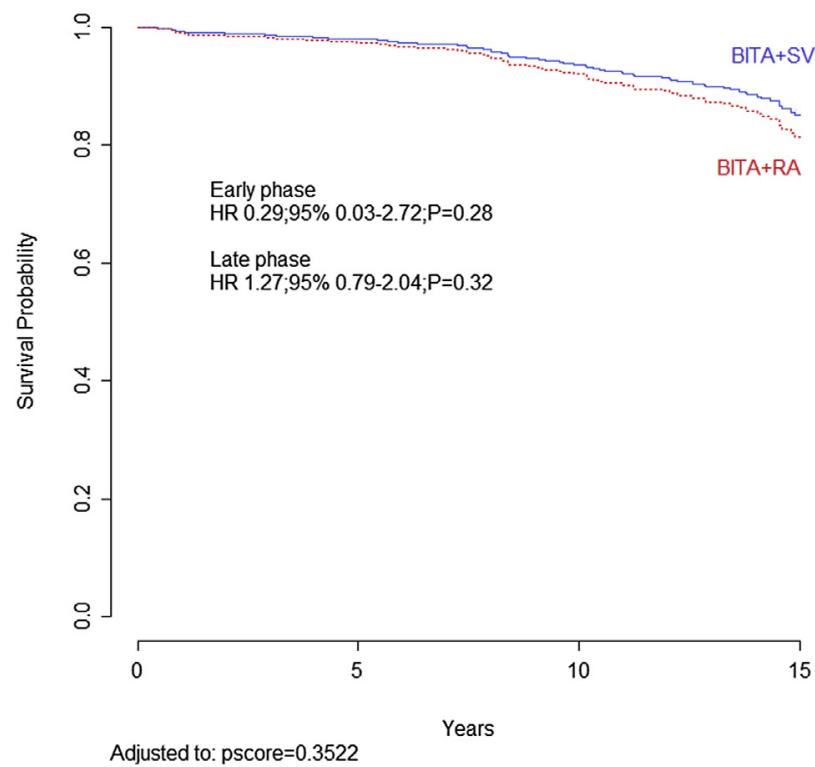

FIGURE 4. Survival probabilities comparison between bilateral internal thoracic artery plus radial artery $(B I T A+R A)$ and bilateral internal thoracic artery plus saphenous vein $(B I T A+S V)$ groups in a time-segmented, propensity score $(P S)$-adjusted analysis. $H R$, Hazard ratio.
The lack of survival benefit provided by using the RA as a third graft might be partially explained by the determinant role of the 2 internal thoracic arteries, which were likely used to graft the 2 most important myocardial territories with the RA left to graft the third territory in order of clinical significance. ${ }^{19}$ In this case, the choice of preferring the RA to SV would have limited prognostic implication. Moreover, Hayward and Buxton ${ }^{20}$ have previously reported on angiographic follow-up of a limited number of RAs used to graft the third and fourth targets in the Radial Artery Patency and Clinical Outcomes study. These were found to have poorer patency rate than vein grafts when placed to the third and fourth positions, thus suggesting the hypothesis that venous conduits might be preferable for third and fourth grafts. This analysis was largely underpowered, however, for conclusions to be drawn. Nevertheless, it is well demonstrated that the RA patency is largely related to the magnitude of the vascular bed for runoff, which is influenced not only by the degree of target stenosis but also by the vessel diameter, diffuseness of disease, left or right dominance, and quality of the distal arterial bed. ${ }^{16,17,20}$ We can speculate that the angiographic superiority of the RA relative to SV might be lost when the RA is used to graft the third target in order of expected runoff, thus eliminating any potential survival benefit. It can be argued that our study population was highly selected with low burden of comorbidities and that it does not represent the majority of patients commonly referred for CABG. A multiple arterial graft strategy is usually adopted, however, for patients at low risk and with prolonged life expectancy. In fact, its beneficial impact on survival may be delayed by as much as 7 to 10 years but persists beyond that period. This strategy therefore may be less appreciated in older patients with coexistent morbidities and limited life expectancy. ${ }^{21-24}$ Of note, in the largest 


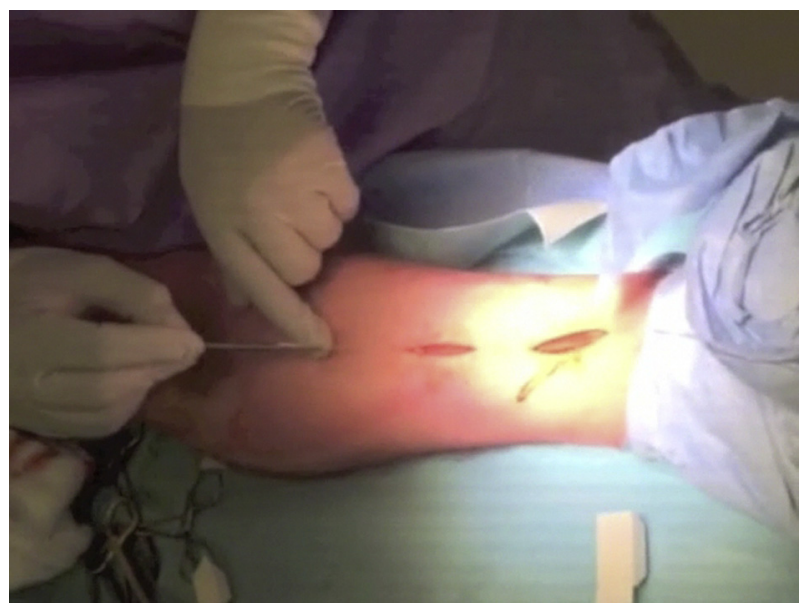

VIDEO 1. Technique for harvesting the saphenous vein. Video available at http://www.jtcvsonline.org/article/S0022-5223(16)30262-8/addons.

randomized trial investigating the impact of using a second arterial graft, ${ }^{25}$ mean age at randomization was 63 years and the prevalence of diabetes with insulin therapy was only $5.6 \%$.

The main limitation of our study is that no follow-up data were available to compare the groups with respect to the cause of death (cardiac vs noncardiac), recurrence of angina, need for repeated revascularization, and graft patency. All-cause mortality may not be an adequate outcome to assess clinical difference in our highly selected low-risk patient population.

As a consequence, the conflicting findings in the literature may be partially explained by different patient selection. Moreover, the relatively small sample size can partially account for lack of survival benefit by using the RA. The nonsignificant trend toward lower survival probabilities in the BITA+RA group, however, also reported by others, ${ }^{4,5}$ limits the potential role of type II error in rejecting the hypothesis of the superiority of the RA. Finally, the study was observational on prospectively collected data, and selection bias cannot be excluded despite PS adjustment.

In conclusion, we found that long-term survival in a highly selected group of patients undergoing BITA grafting was not extended by using the RA as the third arterial conduit in preference to SV in patients undergoing first-time coronary revascularization.

\section{Conflict of Interest Statement}

Authors have nothing to disclose with regard to commercial support.

\section{References} 1. Lytle BW, Loop FD, Cosgrove DM, Ratliff NB, Easley K, Taylor PC. Long-term
(5 to 12 years) serial studies of internal mammary artery and saphenous vein cor-
onary bypass grafts. J Thorac Cardiovasc Surg. 1985;89:248-58.
2. Lytle BW, Blackstone EH, Loop FD, Houghtaling PL, Arnold JH, Akhrass R, et al. Two internal thoracic artery grafts are better than one. J Thorac Cardiovasc Surg. 1999;117:855-72.

3. Shi WY, Hayward PA, Tatoulis J, Rosalion A, Newcomb AE, Fuller JA, et al. Are all forms of total arterial revascularization equal? A comparison of single versus bilateral internal thoracic artery grafting strategies. J Thorac Cardiovasc Surg. 2015;150:1526-33. 1534.e1-3; discussion 1533-4.

4. Di Mauro M, Contini M, Iacò AL, Bivona A, Gagliardi M, Varone E, et al. Bilateral internal thoracic artery on the left side: a propensity score-matched study of impact of the third conduit on the right side. J Thorac Cardiovasc Surg. 2009; 137:869-74.

5. Locker C, Schaff HV, Dearani JA, Joyce LD, Park SJ, Burkhart HM, et al. Multiple arterial grafts improve late survival of patients undergoing coronary artery bypass graft surgery: analysis of 8622 patients with multivessel disease. Circulation. 2012;126:1023-30.

6. Grau JB, Kuschner CE, Johnson CK, Ferrari G, Zapolanski A, Brizzio ME, et al. The effects of using a radial artery in patients already receiving bilateral internal mammary arteries during coronary bypass grafting: 30-day outcomes and 14year survival in a propensity-matched cohort. Eur J Cardiothorac Surg. 2016; 49:203-10.

7. Mohammadi S, Dagenais F, Voisine P, Dumont E, Charbonneau E, Marzouk M, et al. Impact of the radial artery as an additional arterial conduit during in-situ bilateral internal mammary artery grafting: a propensity score-matched study. Ann Thorac Surg. 2016;101:913-8.

8. Lonjon G, Boutron I, Trinquart L, Ahmad N, Aim F, Nizard R, et al. Comparison of treatment effect estimates from prospective nonrandomized studies with propensity score analysis and randomized controlled trials of surgical procedures. Ann Surg. 2014;259:18-25.

9. Angelini GD, Breckenridge IM, Williams HM, Newby AC. A surgical preparative technique for coronary bypass grafts of human saphenous vein which preserves medial and endothelial functional integrity. J Thorac Cardiovasc Surg. 1987:94:393-8.

10. Caputo M, Reeves B, Marchetto G, Mahesh B, Lim K, Angelini GD. Radial versus right internal thoracic artery as second arterial conduit for coronary surgery: early and midterm outcomes. J Thorac Cardiovasc Surg. 2003;126:39-47.

11. Lauer MS, Blackstone EH, Young JB, Topol EJ. Cause of death in clinical research: time for a reassessment? J Am Coll Cardiol. 1999;34:618-20.

12. Austin PC. A tutorial and case study in propensity score analysis: an application to estimating the effect of in-hospital smoking cessation counseling on mortality. Multivariate Behav Res. 2011;46:119-51.

13. Cohen J. Statistical power analysis for the behavioral sciences. 2nd ed. Hillsdale (NJ): Lawrence Erlbaum Associates Publishers; 1988.

14. Medalion B, Mohr R, Ben-Gal Y, Nesher N, Kramer A, Eliyahu S, et al. Arterial coronary artery bypass grafting is safe and effective in elderly patients. J Thorac Cardiovasc Surg. 2015;150:607-12.

15. Hayward PA, Gordon IR, Hare DL, Matalanis G, Horrigan ML, Rosalion A, et al. Comparable patencies of the radial artery and right internal thoracic artery or saphenous vein beyond 5 years: results from the Radial Artery Patency and Clinical Outcomes trial. J Thorac Cardiovasc Surg. 2010;139:60-5; discussion 65-7.

16. Possati G, Gaudino M, Alessandrini F, Luciani N, Glieca F, Trani C, et al. Midterm clinical and angiographic results of radial artery grafts used for myocardial revascularization. J Thorac Cardiovasc Surg. 1998;116:1015-21.

17. Nakajima H, Kobayashi J, Toda K, Fujita T, Shimahara Y, Kasahara Y, et al. Determinants for successful sequential radial artery grafting to the left circumflex and right coronary arteries. Interact Cardiovasc Thorac Surg. 2011;12:125-9.

18. Kieser TM, Rose MS, Aluthman U, Montgomery M, Louie T, Belenkie I. Toward zero: deep sternal wound infection after 1001 consecutive coronary artery bypass procedures using arterial grafts: implications for diabetic patients. J Thorac Cardiovasc Surg. 2014;148:1887-95.

19. Claessen BE, Dangas GD, Godino C, Henriques JP, Leon MB, Park SJ, et al. Impact of target vessel on long-term survival after percutaneous coronary intervention for chronic total occlusions. Catheter Cardiovasc Interv. 2013;82:76-82.

20. Hayward PA, Buxton BF. Contemporary coronary graft patency: 5-year observational data from a randomized trial of conduits. Ann Thorac Surg. 2007;84:795-9.

21. Benedetto U, Amrani M, Raja SG. Harefield Cardiac Outcomes Research Group. Guidance for the use of bilateral internal thoracic arteries according to survival benefit across age groups. J Thorac Cardiovasc Surg. 2014;148:2706-11.

22. Benedetto U, Codispoti M. Age cutoff for the loss of survival benefit from use of radial artery in coronary artery bypass grafting. J Thorac Cardiovasc Surg. 2013; 146:1078-84; discussion 1084-5. 
23. Kieser TM, Lewin AM, Graham MM, Martin BJ, Galbraith PD, Rabi DM, et al. Outcomes associated with bilateral internal thoracic artery grafting: the importance of age. Ann Thorac Surg. 2011;92:1269-75; discussion 1275-6.

24. Mohammadi S, Dagenais F, Doyle D, Mathieu P, Baillot R, Charbonneau E, et al. Age cut-off for the loss of benefit from bilateral internal thoracic artery grafting. Eur J Cardiothorac Surg. 2008:33:977-82.

25. Taggart DP, Altman DG, Gray AM, Lees B, Nugara F, Yu LM, et al; ART Investigators. Randomized trial to compare bilateral vs. single internal mammary cor- onary artery bypass grafting: 1-year results of the Arterial Revascularisation Tria (ART). Eur Heart J. 2010;31:2470-81.

Key Words: coronary artery bypass grafting, multiple arterial grafting, radial artery, bilateral internal thoracic arteries, survival

Readers who found these articles interesting may also like to read the following papers found in recent and future issues of our sister publications, Seminars in Thoracic and Cardiovascular Surgery and Operative Techniques in Thoracic and Cardiovascular Surgery!

\section{Acquired: Coronary Artery Disease}

Original Submissions: Micromorphology of Skeletonized and Pedicled Internal Thoracic and Radial Arteries. Sergey Mamchur. Semin Thorac Cardiovasc Surg 2015; Summer; 27(2):115-120.

Editorial Commentary: Harvesting Arterial Grafts: Barebones or More. Faisal G. Bakaeen. Semin Thorac Cardiovasc Surg 2015; 27(2):121-122. 

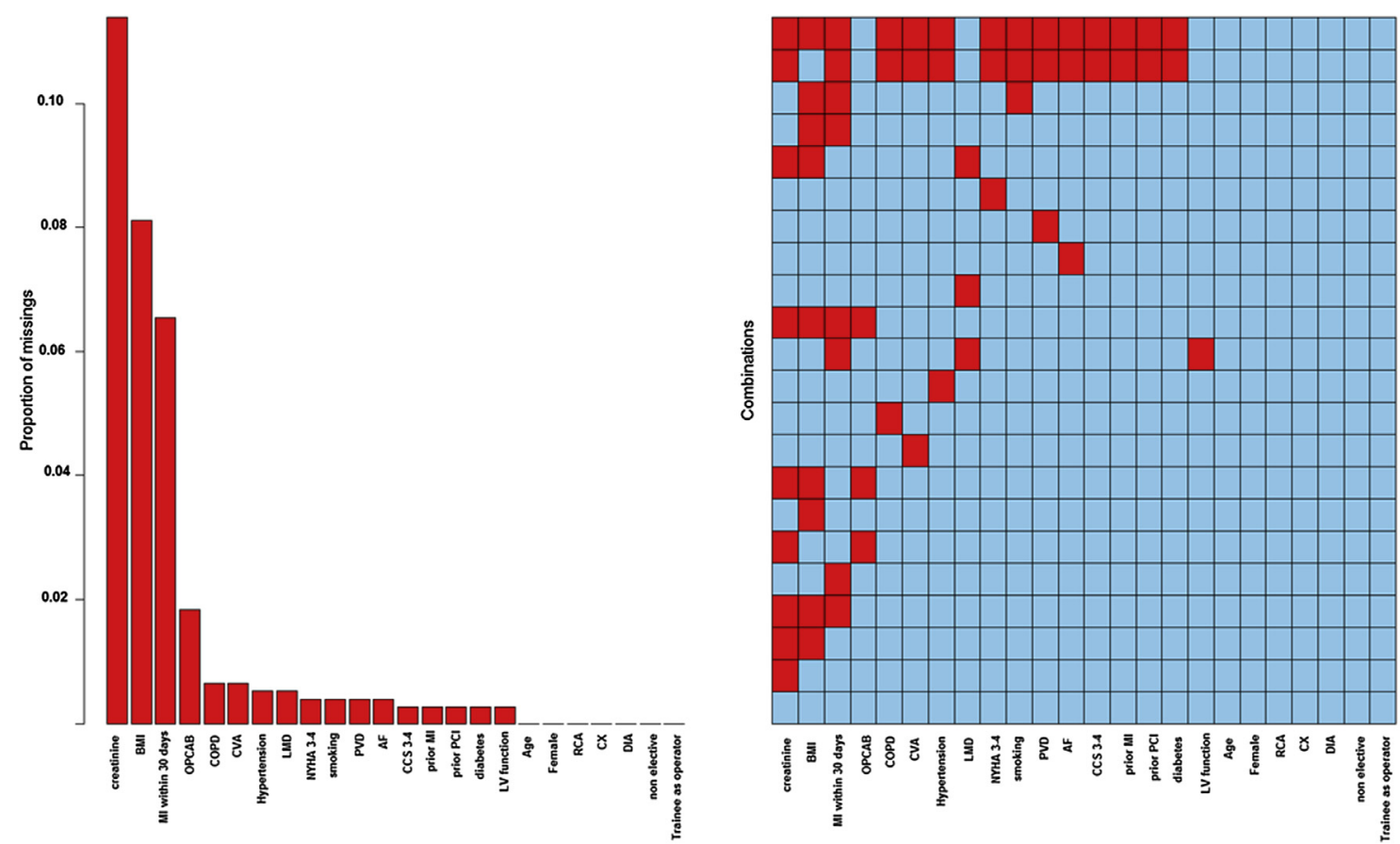

FIGURE E1. Missing data rate for individual variables (left) and their combinations (right). BMI, Body mass index; $O P C A B$, off-pump coronary artery bypass grafting; $C O P D$, chronic obstructive pulmonary disease; $C V A$, cerebrovascular accident; $L M D$, left main coronary artery disease; $N Y H A$, New York Heart Association functional class; $P V D$, peripheral vascular disease; $A F$, atrial fibrillation; $C C S$, Canadian Cardiovascular Society class; $M I$, myocardial infarction; $P C I$, percutaneous coronary intervention; $L V$, left ventricular; $R C A$, right coronary artery; $C X$, circumflex coronary artery; $D I A$, diagonal coronary artery. 
TABLE E1. Amount of missing values in each variable in the unmatched dataset $(N=764)$

\begin{tabular}{|c|c|c|}
\hline Variables & No. & $\%$ \\
\hline Creatinine $\geq 200 \mathrm{mmol} / \mathrm{L}$ & 87 & 11 \\
\hline BMI & 62 & 8 \\
\hline MI within $30 \mathrm{~d}$ & 50 & 6 \\
\hline OPCAB & 14 & 2 \\
\hline COPD & 5 & 0.6 \\
\hline CVA & 5 & 0.6 \\
\hline Hypertension & 4 & 0.5 \\
\hline LMD & 4 & 0.5 \\
\hline NYHA 3-4 & 3 & 0.4 \\
\hline Smoking & 3 & 0.4 \\
\hline PVD & 3 & 0.4 \\
\hline $\mathrm{AF}$ & 3 & 0.4 \\
\hline CCS 3-4 & 2 & 0.3 \\
\hline Previous MI & 2 & 0.3 \\
\hline Previous PCI & 2 & 0.3 \\
\hline Diabetes & 2 & 0.3 \\
\hline LV function & 2 & 0.3 \\
\hline Age & 0 & 0 \\
\hline Female & 0 & 0 \\
\hline $\mathrm{RCA}$ & 0 & 0 \\
\hline $\mathrm{CX}$ & 0 & 0 \\
\hline DIA & 0 & 0 \\
\hline Nonelective & 0 & 0 \\
\hline Trainee & 0 & 0 \\
\hline \multicolumn{3}{|c|}{$\begin{array}{l}B M I \text {, Body mass index; } M I \text {, myocardial infarction; } O P C A B \text {, off-pump coronary artery } \\
\text { bypass; } C O P D \text {, chronic obstructive pulmonary disease; } C V A \text {, previous cerebrovascu- } \\
\text { lar accident; } L M D \text {, left main disease; } N Y H A \text {, New York Heart Association functional } \\
\text { class; } P V D \text {, peripheral vascular disease; } A F \text {, preoperative atrial fibrillation; } C C S \text {, Ca- } \\
\text { nadian Cardiovascular Society class; } P C I \text {, percutaneous coronary intervention; } L V \text {, } \\
\text { left ventricular; } R C A \text {, right coronary artery; } C X \text {, circumflex coronary artery; } D I A \text {, di- } \\
\text { agonal coronary artery. }\end{array}$} \\
\hline
\end{tabular}

